\title{
Qualidade dos frutos de crambe durante o armazenamento ${ }^{1}$
}

\author{
Lílian Moreira Costa ${ }^{2 *}$, Osvaldo Resende², Douglas Nascimento Gonçalves², \\ Kelly Aparecida Sousa ${ }^{2}$
}

\begin{abstract}
RESUMO - Em sementes armazenadas sob condições adequadas, a velocidade do processo de deterioração pode ser diminuída, permitindo a conservação da viabilidade das mesmas por período mais prolongado do que o obtido em condições naturais. Objetivou-se no presente trabalho avaliar a qualidade dos frutos de Crambe abyssinica armazenados em diferentes condições ambientais. Foram utilizados frutos de crambe com teor de agua de $6 \%$ b.u. Os testes de condutividade elétrica, absorção de água, porcentagem de germinação e índice de velocidade de germinação (IVG) foram realizados no início do experimento ( 0 meses) e a cada 2 meses, durante um ano. O armazenamento foi realizado em três condições distintas: condição ambiente $\left(26 \pm 3{ }^{\circ} \mathrm{C} ; 55 \pm 12 \%\right.$ Umidade Relativa - UR), câmara refrigerada do tipo B.O.D. $\left(5 \pm 1{ }^{\circ} \mathrm{C} ; 79 \pm 5 \%\right.$ UR) e câmara climatizada com aparelho de ar condicionado ( $18 \pm 1{ }^{\circ} \mathrm{C} ; 53 \pm 7 \%$ UR). A câmara climatizada $\left(18 \pm 1{ }^{\circ} \mathrm{C} ; 53 \pm 7 \%\right.$ UR) conserva melhor a qualidade dos frutos de crambe em relação à condição ambiente $\left(26 \pm 3{ }^{\circ} \mathrm{C} ; 55 \pm 12 \% \mathrm{UR}\right)$ e câmara refrigerada do tipo B.O.D. $\left(5 \pm 1{ }^{\circ} \mathrm{C} ; 79 \pm 5 \%\right.$ UR). $\mathrm{O}$ armazenamento dos frutos por doze meses, nos três ambientes analisados, promove a quebra de dormência das sementes.
\end{abstract}

Termos para indexação: qualidade pós-colheita, Crambe abyssinica, condições de armazenamento

\section{Crambe fruit quality during storage}

\begin{abstract}
The speed of the deterioration process in seeds stored under proper conditions can be reduced, and seed viability can be maintained for longer than under natural conditions. The aim of this study was to evaluate Crambe abyssinica fruit quality for storage under different environmental conditions. The initial moisture content of crambe seeds was $6 \%$ w.b. The electrical conductivity, water absorption, germination and germination speed index (GSI) were determined at the beginning ( 0 months) and every two months for one year. Seeds were stored under three different conditions: normal environment $\left(26 \pm 3{ }^{\circ} \mathrm{C}, 55 \pm 12 \%\right.$ Relative Humidity - $\left.\mathrm{RH}\right)$, refrigerated type B.O.D. $\left(5 \pm 1^{\circ} \mathrm{C}, 79 \pm 5 \% \mathrm{RH}\right)$ and in a climate chamber with air conditioning $\left(18 \pm 1{ }^{\circ} \mathrm{C}, 53 \pm 7 \%\right.$ $\mathrm{RH})$. The climate chamber $\left(18 \pm 1{ }^{\circ} \mathrm{C}, 53 \pm 7 \% \mathrm{RH}\right)$ maintains the best crambe fruit quality compared to the normal environment $\left(26 \pm 3{ }^{\circ} \mathrm{C}, 55 \pm 12 \% \mathrm{RH}\right)$ and the refrigerated type B.O.D. $\left(5 \pm 1{ }^{\circ} \mathrm{C}, 79 \pm 5 \%\right.$ $\mathrm{RH})$. Fruits stored for twelve months in the three environments caused the seed dormancy to breakdown.
\end{abstract}

Index terms: postharvest quality, Crambe abyssinica, storage conditions.

\section{Introdução}

As diretrizes básicas do Programa Brasileiro de Produção de Biodiesel têm por objetivo destacar o Brasil na produção de combustíveis renováveis, uma vez que o país possui vantagens comparativas em relação aos demais como disponibilidade de terras para a expansão da agricultura, água e energia suficientes para praticar uma agricultura de produção de energia de forma competitiva (Benedetti et al., 2006).

\footnotetext{
${ }^{1}$ Submetido em 18/02/2011. Aceito para publicação em 22/09/2011.

${ }^{2}$ Instituto Federal Goiano, Caixa Postal 66, 75901-970 - Rio Verde, GO, Brasil.

*Autor para correspondência <lmctpg@yahoo.com.br>
} 
Várias oleaginosas estão sendo testadas ou já usadas para a produção de biodiesel como soja, mamona, dendê, girassol, amendoim, crambe, nabo forrageiro, colza, babaçu entre outras (Mello et al., 2007). O crambe (Crambe abyssinica) é uma planta da família das Brassicaceae que surge como alternativa para a produção de matéria-prima visando à obtenção de biocombustível. Esta cultura apresenta como vantagens uma boa produção, características de tolerância à seca e geada e ainda, precocidade no ciclo com duração de, aproximadamente, 90 dias. Devido a estas características, o crambe pode ser cultivado na safra de inverno, com a semeadura realizada logo depois da colheita da soja, apresentando-se como alternativa para o plantio da safrinha. Neste caso, o uso de sementes de qualidade superior certamente contribuirá decisivamente para que as metas de produção sejam alcançadas. Nesse contexto, o armazenamento adequado das sementes se faz necessário para garantir a qualidade e o bom desempenho da cultura no campo.

De acordo com Toledo et al. (2009), a capacidade das sementes manterem sua qualidade durante o período de armazenamento é influenciada por diversos fatores, dentre eles o teor de água com que a semente foi armazenada, embalagens de conservação, temperatura e umidade relativa do ar do ambiente de armazenamento. Segundo Schmidt (2000), a perda de viabilidade das sementes é decorrente do processo de deterioração avançado, que tem início logo após a maturidade fisiológica, pois, pequenos danos são reversíveis e possíveis de serem reparados pelas sementes.

Em sementes armazenadas sob condições adequadas, a velocidade do processo de deterioração pode diminuir, permitindo a conservação da sua viabilidade por período mais longo do que o obtido em condições naturais de armazenamento (Figliolia e Piña-Rodrigues, 1995). A umidade relativa do ar e a temperatura do ambiente de armazenamento são os principais fatores que afetam a qualidade das sementes durante o armazenamento. Condições de elevada umidade relativa do ar podem proporcionar o reinício das atividades metabólicas do embrião, enquanto que temperaturas elevadas ocasionam aumento da atividade respiratória e esgotamento das substâncias de reserva acumuladas (Aguiar, 1995). Tais condições podem favorecer a ação de fungos e insetos, os quais aceleram a deterioração das sementes (Carvalho e Nakagawa, 2000).

A conservação da qualidade fisiológica das sementes está também relacionada ao tipo de embalagem utilizada, conforme a maior ou menor facilidade que apresentam para as trocas de vapor d'água entre as sementes e a atmosfera do ambiente em que estão armazenadas (Marcos Filho, 2005). A qualidade de sementes não pode ser melhorada durante o armazenamento, mas pode ser preservada quando as condições de conservação são favoráveis. Segundo Pádua e Vieira (2001), lotes de sementes com porcentagens de germinação semelhantes, mas com diferentes níveis de vigor, podem apresentar comportamentos diferenciados em relação à deterioração, dependendo das condições de armazenamento.

A deterioração é um dos grandes problemas do armazenamento de sementes, principalmente das oleagenosas (Braccini et al., 2001). De acordo com Marcos Filho (2005), para a melhor conservação das sementes ortodoxas, o ambiente com umidade relativa e temperatura mais baixas tem se mostrado adequado, já que essas condições permitem manutenção de baixo nível de atividade de reações químicas e preservação do poder germinativo e do vigor das sementes. Os fatores que afetam a germinação das sementes são: genótipo das plantas, condições climáticas predominantes durante a maturação, grau de injúrias mecânicas, condições ambientais de armazenamento, ataques de microrganismos e insetos, densidade e tamanho das sementes, idade das sementes, disponibilidade de água e temperatura durante a embebição (Carvalho e Nakagawa, 2000).

Para avaliação da danificação mecânica ocorrida nas sementes podem ser utilizadas as análises de condutividade elétrica e de absorção de água. Segundo Vieira et al. (2002), o teste de condutividade elétrica avalia a qualidade das sementes indiretamente por meio da determinação da quantidade de lixiviados na solução de embebição das sementes.

A reidratação de materiais é um processo complexo que tem como objetivo reconstituir as características originais do produto, quando submetido ao contato com uma fase líquida (Bilbao-Sáinz et al., 2005). A absorção de água depende da diferença entre o teor de água de saturação e o teor de água em um determinado tempo, chamada força motriz (Resio et al., 2005). Durante a embebição, a água é difundida para o interior da semente, promovendo o aumento do seu volume, sendo influenciada, principalmente, pela temperatura da solução de embebição (Bayram et al., 2004). Assim, a absorção de água é um bom parâmetro para análise da danificação mecânica ocorrida, pelo fato de seus valores estarem ligados aos danos causados no tegumento e na estrutura dos grãos, principalmente em função do armazenamento.

O teste de germinação é o principal parâmetro utilizado para a avaliação da qualidade fisiológica das sementes e permite conhecer o potencial de germinação de um lote em condições favoráveis. Os resultados deste teste são utilizados para determinar a taxa de semeadura, para a comparação do valor de lotes e para a comercialização, 
pois possibilita a obtenção de resultados comparáveis entre laboratórios (Carvalho e Nakagawa, 2000).

$\mathrm{Na}$ literatura, existe carência de informações a respeito das alterações que podem ocorrer nas características das sementes de crambe durante o armazenamento. Portanto, torna-se relevante a execução de trabalhos referentes ao assunto, podendo assim gerar informações teóricas e práticas para melhorar a conservação pós-colheita do produto. Assim, por meio deste trabalho, objetivou-se verificar o efeito do tempo e das condições de armazenamento na qualidade das sementes do crambe.

\section{Material e Métodos}

Para a realização deste trabalho foram utilizados frutos de crambe (Crambe abyssinica), os quais são síliquas, inicialmente verdes, mas que se tornam amarelados com a maturidade. Cada fruto contém uma única semente esférica, de cor verde ou marrom esverdeado. Os frutos da cultivar FMS Brilhante desenvolvida pela Fundação MS, foram produzidos na safra de 2009 no Campo Experimental do Instituto Federal de Educação Ciência e Tecnologia Goiano - campus Rio Verde (IFGoiano-campus Rio Verde), localizado em Rio Verde-GO a 17 47' 53" de latitude (S) e $51^{\circ} 55^{\prime} 53^{\prime}$ " de longitude (W). O experimento foi realizado nos Laboratórios de Pós-colheita de Produtos Vegetais e de Sementes (IF Goiano-Campus Rio Verde). Foi realizada a colheita manual dos frutos de crambe, quando se verificou que o teor de água era de $6 \%$ b.u., determinado por gravimetria, utilizando-se estufa a $105 \pm 3{ }^{\circ} \mathrm{C}$, durante 24 horas, em três repetições (Brasil, 2009). Os frutos foram acondicionados em potes de vidro cobertos com tecido tipo voal no dia 11 de agosto de 2009 ao dia 11 de agosto de 2010, tendo $400 \mathrm{~g}$ dos frutos em cada recipiente, em três condições distintas: condição ambiente $\left(26 \pm 3{ }^{\circ} \mathrm{C} ; 55 \pm\right.$ $12 \%$ Umidade Relativa - UR), câmara refrigerada do tipo B.O.D. $\left(5 \pm 1{ }^{\circ} \mathrm{C} ; 79 \pm 5 \%\right.$ UR) e câmara climatizada com aparelho de ar condicionado $\left(18 \pm 1{ }^{\circ} \mathrm{C} ; 53 \pm 7 \%\right.$ UR). Durante o armazenamento a UR e a temperatura de todos os ambientes foram registradas por um 'datalogger' digital.

As amostras foram avaliadas aos 0, 2, 4, 6, 8, $10 \mathrm{e}$ 12 meses, em 3 repetições, quanto à absorção de água, condutividade elétrica, porcentagem de germinação e índice de velocidade de germinação (IVG).

Para a determinação da absorção de água, as amostras foram submetidas à hidratação em água destilada durante um período de 12 horas. O teste de absorção de água foi realizado em câmara do tipo B.O.D. com a temperatura regulada para $25 \pm 2{ }^{\circ} \mathrm{C}$. Utilizaram-se copos plásticos (capacidade de $100 \mathrm{~mL}$ ) contendo $75 \mathrm{~mL}$ de água destilada juntamente com $15 \mathrm{~g}$ da amostra, perfazendo uma relação em massa de 5:1. As amostras foram levemente agitadas com um bastão para que todas fossem completamente submersas. Depois do período de hidratação, as amostras foram retiradas dos copos e colocadas sobre papel filtro para escorrimento da água superficial durante dois minutos e, em seguida, pesadas com precisão de duas casas decimais (0,01 g). O teor de água depois da absorção foi obtido por meio da seguinte equação:

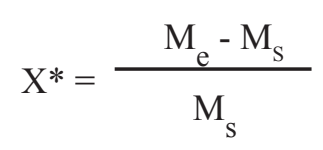

em que,

$\mathrm{X}^{*}$ : teor de água do produto, decimal b.s.

$\mathrm{M}_{\mathrm{e}}$ : massa depois da embebição, $\mathrm{kg}$

$\mathrm{M}_{\mathrm{s}}$ : massa da matéria seca do produto, $\mathrm{kg}$

O teste de condutividade elétrica (CE) foi realizado segundo metodologia descrita por Vieira e Krzyzanowski (1999). Foram utilizadas quatro subamostras de 50 frutos, de cada tratamento, pesadas com precisão de duas casas decimais $(0,01 \mathrm{~g})$. As amostras foram colocadas para embeber em copos plásticos com $75 \mathrm{~mL}$ de água deionizada e mantida em câmara do tipo B.O.D. com temperatura controlada a $25^{\circ} \mathrm{C}$, durante 24 horas. As soluções contendo os frutos foram levemente agitadas para uniformização dos lixiviados e, imediatamente, procedeu-se à leitura em condutivímetro digital portátil modelo CD-850 "INSTRUTHERM", sendo os resultados divididos pela massa dos 50 frutos e expressos em $\mu \mathrm{S} \mathrm{cm}^{-1} \mathrm{~g}^{-1}$ de sementes.

$O$ teste de germinação foi conduzido com quatro subamostras de 30 frutos de cada tratamento, acondicionadas em caixas tipo "gerbox" sobre papel mata-borrão umedecido com água destilada, equivalente a 2,5 vezes a massa do substrato seco. Em seguida, foram mantidas em germinador tipo "Mangelsdorf" regulado a uma temperatura constante de $25 \pm 2{ }^{\circ} \mathrm{C}$. As avaliaçoões foram realizadas a cada dois dias a partir do $2^{\circ}$ dia após a semeadura, até completar 32 dias, segundo os critérios estabelecidos nas Regras para Análise de Sementes (Brasil, 2009). Computou-se a porcentagem média de germinação e o índice de velocidade de germinação ( $\mathrm{IVG}=$ $\mathrm{n}_{1} \cdot \mathrm{d}_{1}{ }^{-1}+\mathrm{n}_{2} \cdot \mathrm{d}_{2}^{-1}+\mathrm{n}_{3} \cdot \mathrm{d}_{3}^{-1} \ldots$ n.d $\mathrm{d}_{\mathrm{n}}^{-1}$; sendo $\mathrm{n}_{1}=$ sementes 
germinadas no primeiro dia da contagem; $\mathrm{n}_{2}=$ sementes germinadas no segundo dia da contagem; $n_{3}=$ sementes germinadas no terceiro dia da contagem; $n_{n}=$ sementes germinadas no enésimo dia da contagem; $d_{1}=$ primeiro dia, $d_{2}=$ segundo dia; $d_{3}=$ terceiro dia, $d_{n}=$ enésimo dia).

Utilizou-se o delineamento inteiramente casualizado, segundo esquema de parcela subdividida, sendo três condições de armazenamento (condição ambiente, câmara refrigerada e câmara climatizada) nas parcelas e os meses de avaliação nas subparcelas, e as médias foram comparadas pelo teste de Tukey, a 5\% de probabilidade.

\section{Resultados e Discussão}

Nas Figuras 1 e 2 estão apresentados os valores médios mensais da temperatura e da umidade relativa do ar nos três ambientes de armazenamento dos frutos de crambe. Verifica-se que a câmara refrigerada promoveu maior umidade relativa, apresentando menores oscilações ao longo do tempo. A condição ambiente apresentou maiores alterações nas condições do ar, em virtude das mudanças climáticas decorrentes das estações do ano. A câmara climatizada apresentou menores valores de umidade relativa devido ao sistema de resfriamento retirar vapor de água desta câmara.

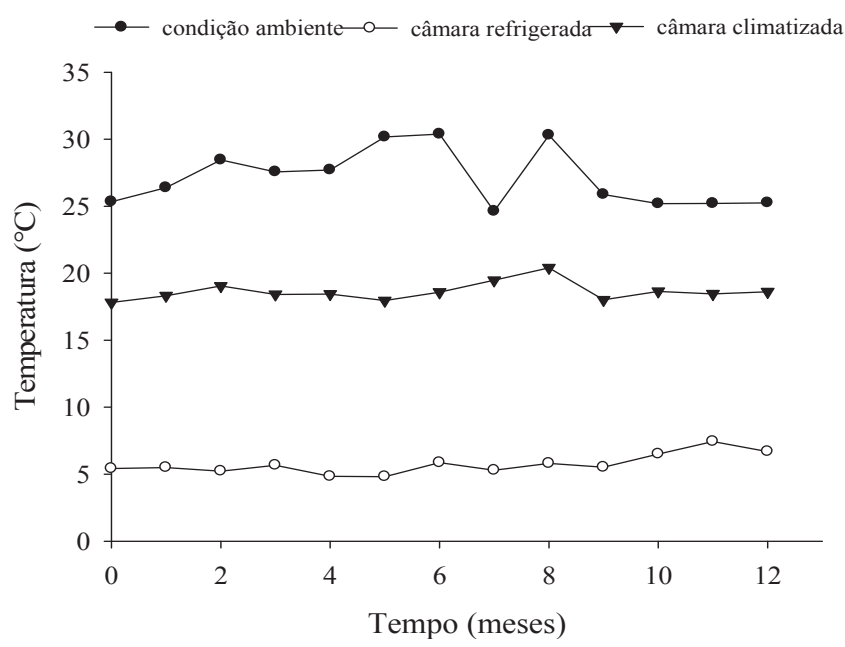

Figura 1. Temperatura média ao longo do armazenamento em três condições distintas: condição ambiente $\left(26 \pm 3{ }^{\circ} \mathrm{C}\right)$, câmara refrigerada $\left(5 \pm 1{ }^{\circ} \mathrm{C}\right)$ e câmara climatizada $\left(18 \pm 1^{\circ} \mathrm{C}\right)$.

Na Tabela 1 verifica-se que todas as variáveis analisadas foram significativas, com exceção do teor de água ao longo do tempo (meses) e a interação entre o ambiente e os meses de armazenamento.

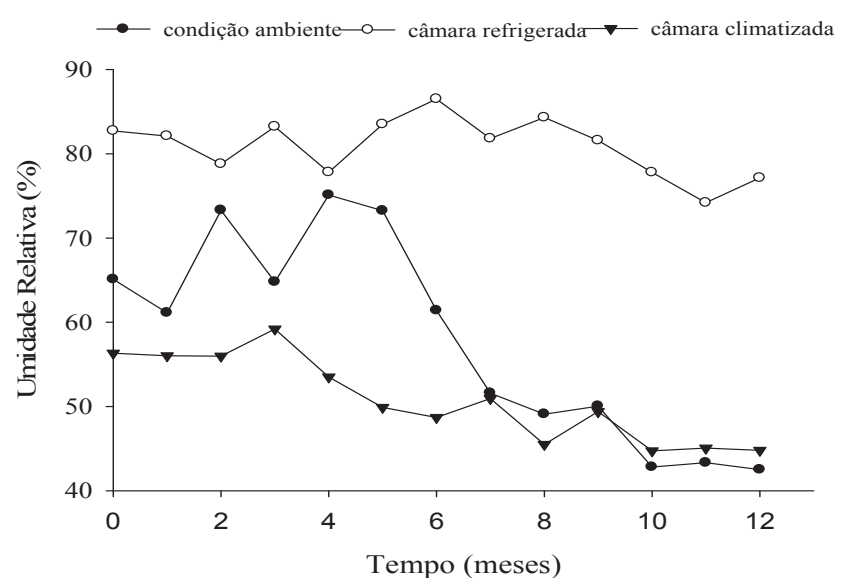

Figura 2. Umidade relativa média ao longo do armazenamento em três condições distintas: condição ambiente $(55 \pm 12 \%$ Umidade Relativa - UR), câmara refrigerada ( $79 \pm 5 \%$ UR) e câmara climatizada ( $53 \pm 7 \%$ UR).

Os frutos armazenados na câmara refrigerada apresentaram maior teor de água, enquanto os na câmara climatizada não diferiram da condição ambiente quanto a estes teores (Tabela 2). Nas três condições de armazenamento, não foram identificadas diferenças significativas do teor de água ao longo do tempo. Este comportamento pode ser explicado devido a temperatura ser mais baixa no armazenamento em câmara refrigerada e a umidade relativa mais alta (Figuras 1 e 2). Desta forma, os frutos entraram em equilíbrio higroscópico com as condições de temperatura e umidade relativa dos ambientes do armazenamento. De acordo com Carvalho e Nakagawa (2000), mudanças na temperatura e umidade relativa do ar provocam constantes ajustes no teor de água das sementes armazenadas em embalagens permeáveis ao vapor de água.

A absorção de água pelos frutos foi semelhante nas três condições de armazenamento, com exceção do $4^{\circ}$ mês de armazenamento que na câmara refrigerada foi menor que na condição ambiente e no $10^{\circ}$ mês, cuja absorção foi menor nos frutos acondicionados na câmara climatizada (Tabela 3). Possivelmente, estas alterações nos valores da absorção de água pelos frutos devem-se às variações de temperatura e umidade relativas nos ambientes de armazenamento.

Ao longo do tempo, a absorção de água praticamente não se alterou nas três condições de armazenamento, 
exceto para o $10^{\circ}$ mês na câmara refrigerada que apresentou um valor mais elevado. Mesmo assim, ao final dos 12 meses de armazenamento a absorção de água não apresentou diferença significativa em relação ao valor inicial para as três condições de armazenamento analisadas (Tabela 3). A entrada e a distribuição da água nas sementes, reguladas pelo potencial de água celular, ocorrem tanto por capilaridade como por difusão, no sentido do maior para o menor potencial hídrico. De acordo com Bewley e Black (1994), a quantidade de água absorvida depende da espécie, semente, variedade, ou cultivar, temperatura ambiente, composição química da semente, teor de água inicial, natureza do tegumento e quantidade de água disponível. Desta forma, a embebição tem sido entendida como um processo físico relacionado, principalmente, com as características de permeabilidade do envoltório e com as propriedades dos coloides constituintes das sementes (Bewley e Black, 1994; Carvalho e Nakagawa, 2000). Segundo Ullmann et al. (2010), a absorção de água é um bom parâmetro para análise da danificação mecânica ocorrida, pelo fato de seus valores estarem ligados aos danos causados no tegumento e na estrutura das sementes. Possivelmente a estrutura do fruto de crambe por apresentar um pericarpo rígido e pouco permeável a água, pode ter influenciado nos valores de absorção de água.

Tabela 1. Resumo da análise de variância para teor e absorção de água, condutividade elétrica, porcentagem de germinação e índice de velocidade de germinação (IVG), durante o armazenamento dos frutos de crambe em diferentes ambientes por 12 meses.

\begin{tabular}{cccc}
\hline Variáveis analisadas & Fonte de variação & Quadrados médios & CV $(\%)$ \\
\hline \multirow{2}{*}{ Teor de água } & Ambiente & $0,002924^{* *}$ & 9,94 \\
& Meses & $0,000315^{\mathrm{NS}}$ & 27,78 \\
& Ambiente x Meses & $0,000669^{\mathrm{NS}}$ & \\
\hline \multirow{2}{*}{ Absorção de água } & Ambiente & $0,010748^{*}$ & 3,80 \\
& Meses & $0,008884^{* *}$ & 4,57 \\
& Ambiente x Meses & $0,007248^{* *}$ & \\
\hline \multirow{2}{*}{ Condutividade elétrica } & Ambiente & $7884,83^{*}$ & 7,00 \\
& Meses & $13759,96^{* *}$ & 7,55 \\
Porcentagem de germinação & Ambiente x Meses & $2166,36^{* *}$ & \\
& Ambiente & $5021,90^{* *}$ & 14,55 \\
& Meses & $5885,28^{* *}$ & 10,65 \\
\hline \multirow{2}{*}{ IVG } & Ambiente x Meses & $510,27^{* *}$ & \\
\hline & Ambiente & $67,0235^{* *}$ & 15,81 \\
& Meses & $76,8321^{* *}$ & 15,33 \\
\hline
\end{tabular}

${ }^{* *}$ Significativo a $1 \%$ pelo teste F. ${ }^{*}$ Significativo a $5 \%$ pelo teste F. ${ }^{\text {NS }}$ Não significativo.

Tabela 2. Teor de água (\% b.u.) dos frutos de crambe submetidos ao armazenamento em condição ambiente, câmara refrigerada e câmara climatizada durante 12 meses.

\begin{tabular}{ccccccccc}
\hline \multirow{2}{*}{ Ambientes } & \multicolumn{7}{c}{ Tempo de Armazenamento (meses) } & \multirow{2}{*}{ Média } \\
\cline { 2 - 7 } & 0 & 2 & 4 & 6 & \multicolumn{1}{c}{8} & \multicolumn{1}{c}{10} & \multicolumn{1}{c}{12} & \\
\hline Cond. Ambiente & 6,00 & 7,00 & 8,63 & 6,33 & 7,00 & 5,00 & 4,98 & $6,42 \mathrm{a}$ \\
Câm. Refrigerada & 6,00 & 7,67 & 6,32 & 8,00 & 10,00 & 10,00 & 9,91 & $8,27 \mathrm{~b}$ \\
Câm. Climatizada & 6,00 & 6,67 & 7,82 & 5,67 & 6,00 & 5,00 & 5,29 & $6,06 \mathrm{a}$ \\
\hline Média & 6,00 & 7,11 & 7,59 & 6,67 & 7,67 & 6,67 & 6,73 & \\
\hline
\end{tabular}

As médias seguidas das mesmas letras minúscula na coluna não diferem entre si pelo teste de Tukey a 5\% de probabilidade. 
Tabela 3. Absorção de água (decimal b.s) dos frutos de crambe armazenados em condição ambiente, câmara refrigerada e câmara climatizada por um período de um ano.

\begin{tabular}{clllllll}
\hline \multirow{2}{*}{ Ambientes } & \multicolumn{7}{c}{ Tempo de Armazenamento (meses) } \\
\cline { 2 - 8 } & \multicolumn{1}{c}{0} & \multicolumn{1}{c}{4} & \multicolumn{1}{c}{6} & 8 & 10 & 12 \\
\hline Cond. Ambiente & $0,90 \mathrm{aA}$ & $0,99 \mathrm{aA}$ & $0,92 \mathrm{bA}$ & $0,90 \mathrm{aA}$ & $0,92 \mathrm{aA}$ & $0,95 \mathrm{aA}$ & $0,93 \mathrm{aA}$ \\
Câm. Refrigerada & $0,90 \mathrm{aAB}$ & $0,99 \mathrm{aBC}$ & $0,82 \mathrm{aA}$ & $0,89 \mathrm{aAB}$ & $0,88 \mathrm{aA}$ & $1,02 \mathrm{aC}$ & $0,88 \mathrm{aA}$ \\
Câm. Climatizada & $0,90 \mathrm{aAB}$ & $0,95 \mathrm{aB}$ & $0,90 \mathrm{abB}$ & $0,88 \mathrm{aAB}$ & $0,89 \mathrm{aAB}$ & $0,80 \mathrm{bA}$ & $0,89 \mathrm{aAB}$ \\
\hline
\end{tabular}

As médias seguidas, das mesmas letras minúscula na coluna e maiúscula na linha não diferem entre si pelo teste de Tukey a 5\% de probabilidade.

De uma maneira geral, o crambe armazenado na câmara refrigerada apresentaram menores valores de condutividade elétrica em relação às mantidas nas demais condições de armazenamento, identificados estatisticamente somente no $6^{\circ}$ mês de armazenamento, indicando que o armazenamento nesta condição proporcionou menor lixiviação de eletrólitos e consequentemente melhor conservação. Os valores de condutividade elétrica não se alteraram ao longo do armazenamento na câmara refrigerada, enquanto tenderam a aumentar durante armazenamento a câmara climatizada e condição ambiente (Tabela 4). Estes resultados estão de acordo com os obtidos por Nakagawa et al. (2004), que concluíram que, dentre os ambientes testados, a refrigerador e freezer mostram-se mais favoráveis à conservação de sementes de aveia preta comparativamente ao ambiente de câmara seca.
Segundo Vieira et al. (2002) o teste de condutividade elétrica baseia-se na avaliação indireta da qualidade fisiológica por meio da determinação da quantidade de lixiviados na solução de embebição das sementes. Os menores valores correspondentes à menor liberação de exsudatos indicam altos potenciais fisiológicos (maior vigor), revelando menor intensidade de desorganização dos sistemas de membranas das células. Marques et al. (2002) verificaram eficiência desse teste para diferenciar lotes de sementes de Dalbergia nigra (jacarandá-da-bahia), com alto grau de associação com o teste de germinação, e Santos e Paula (2005) consideraram o teste de condutividade elétrica promissor para diferenciar lotes de sementes de Sebastiania commersoniana (branquilho).

Tabela 4. Condutividade elétrica $\left(\mu \mathrm{S} \mathrm{cm}^{-1} \mathrm{~g}^{-1}\right)$, dos frutos de crambe submetidos ao armazenamento em condição ambiente, câmara refrigerada e câmara climatizada durante 12 meses.

\begin{tabular}{cccccccc}
\hline \multirow{2}{*}{ Ambientes } & \multicolumn{7}{c}{ Tempo de Armazenamento (meses) } \\
\cline { 2 - 8 } & 0 & 2 & 4 & 6 & 8 & 10 & 12 \\
\hline Cond. Ambiente & $367,7 \mathrm{aBC}$ & $315,9 \mathrm{aAB}$ & $291,9 \mathrm{aA}$ & $381,6 \mathrm{bBC}$ & $390,0 \mathrm{aC}$ & $435,2 \mathrm{aC}$ & $426,4 \mathrm{bC}$ \\
Câm. Refrigerada & $367,7 \mathrm{aAB}$ & $337,6 \mathrm{abAB}$ & $299,91 \mathrm{aA}$ & $322,8 \mathrm{aAB}$ & $388,9 \mathrm{aB}$ & $393,0 \mathrm{aB}$ & $356,6 \mathrm{aAB}$ \\
Câm. Climatizada & $367,7 \mathrm{aAB}$ & $387,3 \mathrm{bBC}$ & $304,3 \mathrm{aA}$ & $443,1 \mathrm{cC}$ & $416,3 \mathrm{aBC}$ & $413,6 \mathrm{aBC}$ & $405,6 \mathrm{abBC}$ \\
\hline
\end{tabular}

As médias seguidas, das mesmas letras minúscula na coluna e maiúscula na linha não diferem entre si pelo teste de Tukey a 5\% de probabilidade.

$\mathrm{Na}$ Tabela 5 estão apresentados os valores de porcentagem de germinação das sementes de crambe, durante o armazenamento, por 12 meses em três ambientes distintos. $\mathrm{O}$ potencial germinativo foi mais elevado nas sementes armazenadas a câmara climatizada, para todos os meses de armazenamento exceto para amostra inicial.

Observa-se que as sementes de crambe apresentaram dormência no início do armazenamento. Faria et al. (2012), estudando a qualidade fisiológica das sementes de crambe concluiu que houve um baixo percentual de germinação com valores de 15,$5 ; 20,15 ; 24,65 ; 23,5$ e $10,3 \%$, para as temperaturas de secagem de $30,40,50,60 \mathrm{e}$ $70{ }^{\circ} \mathrm{C}$, respectivamente. Este mecanismo é comum nas sementes recém-colhidas de diversas espécies (Brasil, 2009). Assim pode-se inferir que o ambiente climatizado foi melhor para a quebra da dormência das sementes de crambe. Costa et al. (2012), verificaram que a porcentagem média de sementes de crambe germinadas logo após à secagem nas temperaturas de 23 , 
$30,40,50,60$ e $70{ }^{\circ} \mathrm{C}$ foi de 6,$5 ; 17,1 ; 4,4 ; 7.1 ; 3,5$ e $4,6 \%$ respectivamente, sendo que o aumento da temperatura interferiu negativamente na qualidade fisiológica das sementes. Estes pesquisadores também observaram os baixos valores da germinação e do IVG, indicando a dormência das sementes de crambe recém-colhidas.

Durante o armazenamento, a porcentagem de germinação aumentou nas sementes mantidas em câmara climatizada e condição ambiente, enquanto nas de câmara refrigerada, esse potencial aumentou até o segundo mês, a partir do qual os valores diminuíram e oscilaram (Tabela 5). Acredita-se que os menores valores de umidade relativa da câmara climatizada favoreceram a quebra de dormência nas sementes. Na condição ambiente também houve quebra de dormência das sementes ao longo do tempo, porém em menor intensidade, possivelmente devido aos maiores valores da temperatura que podem ter prejudicado a germinação. Ressalta-se que houve uma maior incidência de fungos nos frutos armazenados a câmara refrigerada, mesmo sendo tratadas com fungicida Vitavax ${ }^{\circledR}$ Thiran 200 sc, conforme indicação comercial para a realização do teste de germinação. Este fato deve-se aos maiores valores da atividade de água destes frutos (superiores a 0,75 , conforme Figura 2) que apresentaram elevados teores de água ao longo do armazenamento.

$O$ estudo de dormência em sementes de crambe se torna necessário ao considerar-se que a capacidade germinativa aumenta com o tempo de armazenamento. Faria et al. (2012), estudando a viabilidade de sementes recém-colhidas de crambe submetidas a diferentes condições de secagem e teores de água, observou um baixo percentual de germinação e ressaltou que as sementes de crambe possuem algum tipo de dormência. Tunes et al. (2010), constataram que o tempo e as condições de armazenamento influenciaram na "quebra" da dormência de sementes de cevada armazenadas em câmara fria e seca e ou ambiente natural, após 6 meses de armazenamento, época apropriada para a semeadura. Cardoso et al. (2004), armazenando soja por oito meses em armazém com sistema de aeração a frio com umidade relativa entre 60 e $70 \%$ e temperatura entre 15 e $27^{\circ} \mathrm{C}$, verificaram uma suave redução na qualidade fisiológica das sementes de soja até os 90 dias de armazenamento, apresentado valores de germinação iguais ou superiores a $80 \%$; após este período houve uma queda acentuada no poder germinativo das sementes.

Freitas et al. (2000), armazenaram sementes de algodoeiro da cultivar ITA-90 em ambiente sem controle de temperatura e de umidade relativa e verificaram que a porcentagem de germinação permaneceu acima do padrão para o comércio, até nove meses de armazenamento. Esses resultados favoráveis foram atribuídos, pelos autores, ao alto vigor inicial e baixo teor de água das sementes que reduziram a velocidade do processo deteriorativo. Essa relação entre vigor e potencial de armazenamento de sementes de algodoeiro também foi verificada por (Pádua e Vieira, 2001).

Assim como ocorreu com a porcentagem de germinação, o índice de velocidade de germinação (IVG) foi mais elevado nas sementes armazenadas a câmara climatizada. Esse índice aumentou significativamente ao longo do tempo nas sementes mantidas à câmara climatizada e condição ambiente, destacando o armazenamento a câmara climatizada, cujos valores do IVG das sementes foram mais elevados (Tabela 6).

Santos e Paula (2005), mostraram que sementes de branquilo diminuem a porcentagem e o índice de velocidade de germinação quando armazenadas por cinco meses em sacos de papel, indicando que além do ambiente do armazenamento, a redução da germinação pode estar relacionada à embalagem utilizada.

Tabela 5. Germinação (\%) das sementes de crambe armazenadas em condição ambiente, câmara refrigerada e câmara climatizada por um período de um ano.

\begin{tabular}{cccccccc}
\hline \multirow{2}{*}{ Ambientes } & \multicolumn{7}{c}{ Tempo de Armazenamento (meses) } \\
\cline { 2 - 8 } & 0 & 2 & 4 & 6 & 8 & 10 & 12 \\
\hline Cond. Ambiente & $7,50 \mathrm{aA}$ & $43,06 \mathrm{aB}$ & $72,78 \mathrm{bCD}$ & $68,61 \mathrm{bC}$ & $88,06 \mathrm{bD}$ & $78,89 \mathrm{bCD}$ & $79,17 \mathrm{bCD}$ \\
Câm. Refrigerada & $5,56 \mathrm{aA}$ & $73,06 \mathrm{bD}$ & $45,28 \mathrm{aB}$ & $52,50 \mathrm{aBC}$ & $63,33 \mathrm{aCD}$ & $51,94 \mathrm{aBC}$ & $44,17 \mathrm{aB}$ \\
Câm. Climatizada & $6,39 \mathrm{aA}$ & $79,17 \mathrm{bB}$ & $93,06 \mathrm{cBC}$ & $87,78 \mathrm{cBC}$ & $96,39 \mathrm{bC}$ & $95,00 \mathrm{cBC}$ & $94,44 \mathrm{cBC}$ \\
\hline
\end{tabular}

As médias seguidas, das mesmas letras minúscula na coluna e maiúscula na linha não diferem entre si pelo teste de Tukey a $5 \%$ de probabilidade. 
Tabela 6. Índice de velocidade de germinação (IVG) das sementes de crambe submetidas ao armazenamento em diferentes condições durante 12 meses.

\begin{tabular}{cccccccc}
\hline \multirow{2}{*}{ Ambientes } & \multicolumn{7}{c}{ Tempo de Armazenamento (meses) } \\
\cline { 2 - 7 } & 0 & 2 & 4 & 6 & 8 & 10 & 12 \\
\hline Cond. Ambiente & $0,46 \mathrm{aA}$ & $3,93 \mathrm{aB}$ & $7,88 \mathrm{bCD}$ & $6,67 \mathrm{bC}$ & $9,48 \mathrm{bD}$ & $8,81 \mathrm{bCD}$ & $7,84 \mathrm{bCD}$ \\
Câm. Refrigerada & $0,37 \mathrm{aA}$ & $6,30 \mathrm{bB}$ & $4,22 \mathrm{aB}$ & $4,26 \mathrm{aB}$ & $6,58 \mathrm{aB}$ & $5,23 \mathrm{aB}$ & $4,51 \mathrm{aB}$ \\
Câm. Climatizada & $0,35 \mathrm{aA}$ & $6,81 \mathrm{bB}$ & $9,54 \mathrm{bBCD}$ & $7,74 \mathrm{bBC}$ & $11,57 \mathrm{cD}$ & $9,80 \mathrm{bCD}$ & $10,78 \mathrm{cD}$ \\
\hline
\end{tabular}

As médias seguidas, das mesmas letras minúscula na coluna e maiúscula na linha não diferem entre si pelo teste de Tukey a $5 \%$ de probabilidade.

\section{Conclusões}

A câmara climatizada com aparelho de ar condicionado $\left(18 \pm 1{ }^{\circ} \mathrm{C} ; 53 \pm 7 \% \mathrm{UR}\right)$ conserva melhor a qualidade dos frutos de crambe em relação à condição ambiente $\left(26 \pm 3^{\circ} \mathrm{C}\right.$; $55 \pm 12 \%$ UR) e à câmara refrigerada do tipo B.O.D. $(5 \pm$ $1{ }^{\circ} \mathrm{C} ; 79 \pm 5 \%$ UR). $\mathrm{O}$ armazenamento dos frutos por doze meses nos três ambientes analisados promove a quebra de dormência das sementes.

\section{Agradecimentos}

À CAPES e ao CNPq, pelo apoio financeiro indispensável à execução do presente trabalho e pela concessão de bolsa de mestrado ao primeiro autor.

\section{Referências}

AGUIAR, I.B. Conservação de sementes. In: SILVA, A.; PIÑARODRIGUES, F.C.M.; FIGLIOLIA, M.B. (Coord.). Manual técnico de sementes florestais. São Paulo: Instituto Florestal, p.33-44. (Série Registros, n.14). 1995. http://www.sciencedirect.com/science/article/pii/ S0260877403001377

BAYRAM, M.; ONER, M.D.; KAYA, A. Influence of soaking on the dimensions and colour of soybean for bulgur production. Journal of Food Engineering, v.61, n.3, p.331-339. 2004.

BENEDETTI, O.; PLÁ, J.A.; RATHMANN, R.; PADULA, A.D. Uma proposta de modelo para avaliar a viabilidade do biodiesel no Brasil. Teoria e Evidência Econômica, v.14, p.81-107, Ed. Especial 2006. http:// www.upf.tche.br/cepeac/download/rev_esp_2006_art4.pdf

BEWLEY, J.D.; BLACK, M. Seeds: physiology of development and germination. 2 nd ed. New York: Plenum Press, 1994. 445p.

BILBAO-SÁINZ, C.; ANDRÉS, A.; FITO, P. Hydration kinetics of dried apple as affected by drying conditions. Journal of Food Engineering, v.68, n.3, p.369-376, 2005. http://www.sciencedirect.com/science/article/ b6t8j-4d2fkw4 2/2/0137ad75eb0d756f127ea94f7952364b
BRACCINI, A.L.; BRACCINI, M.C.L.; SCAPIM, C.A. Mecanismos de deterioração das sementes: aspectos bioquímicos e fisiológicos. Informativo ABRATES, v.11, n.1, p.10-15, 2001. http://www.scielo.br/ scielo.php?script $=$ sci_nlinks\&ref $=27604311 \&$ pid $=$ S0100676220060001 0000600003\&lng=en

BRASIL. Ministério da Agricultura, Pecuária e Abastecimento. Regras para análise de sementes. Ministério da Agricultura, Pecuária e Abastecimento. Secretaria de Defesa Agropecuária. Brasília: MAPA/ ACS, 2009. 395p.http://www.agricultura.gov.br/arq editor/file/ Laborat\%C3\%B3rio/Sementes/Regras\%20para\%20Analise\%20de\%20 Sementes.pdf

CARDOSO, P.C.; BAUDET, L.; PESKE, S.T.; LUCCA FILHO, O.A. Armazenamento em sistema a frio de sementes de soja tratadas com fungicida. Revista Brasileira de Sementes, v.26, n.1, p.15 - 23, 2004. $\mathrm{http} / / /$ www.scielo.br/pdf/rbs/v26n1/a03v26n1.pdf

CARVALHO, N.M.; NAKAGAWA, J. Sementes: ciência, tecnologia e produção. 4.ed. Jaboticabal: FUNEP, 2000. 88p.

COSTA, L.M.; RESENDE, O.; GONÇALVES, D.N.; SOUZA, K.A.; SALES, J.F.; DONADON, J.R. The influence of drying on the physiological quality of crambe fruits. Acta Scientiarum. Agronomy, v.34, n.2, p.213-218, 2012.

FARIA， R.Q.; TEIXEIRA， I.R.; DEVILLA， ASCHERI， D.P.R.; RESENDE, O. Cinética de secagem de sementes de crambe. Revista Brasileira de Engenharia Agrícola e Ambiental, v.16, n.5, p.573-583, 2012. http://www.agriambi.com.br/revista/v16n05/v16n05a14.pdf

FIGLIOLIA, M.B.; PIÑA-RODRIGUES, F.C.M. Manejo de sementes de espécies arbóreas. São Paulo: Instituto Florestal, 1995. 59p. (Série Registros, n.15).

FREITAS, R.A.; DIAS, D.C.F.S.; CECON, P.R.; REIS, M.S. Qualidade fisiológica e sanitária de sementes de algodão durante o armazenamento. Revista Brasileira de Sementes, v.22, n.2, p.94-101, 2000. http://www. abrates.org.br/revista/artigospublicados/indice.php? $\mathrm{v}=22 \& \mathrm{n}=2$

MARCOS-FILHO, J. Fisiologia de sementes de plantas cultivadas. Piracicaba: FEALQ, 2005. 495p.

MARQUES, M.A.; PAULA, R.C.; RODRIGUES, T.J.D. Adequação do teste de condutividade elétrica para determinar a qualidade fisiológica 
de sementes de jacarandá-da-bahia (Dalbergia nigra (Vell.) Fr. All. ex Benth.). Revista Brasileira de Sementes, v.24, n.1, p.271-278, 2002. http://www.abrates.org.br/revista/artigos/2002/v24n1/artigo38.pdf

MELLO, F.O.T.; PAULILLO, L.F.; VIAN, C.E.F. O Biodiesel no Brasil: Panorama, perspectivas e desafios. Informações Econômicas, v.37, n.1, p.28-40, 2007. http://www.funepe.edu.br:91/funepe/professores/ materiais/10/IE_Biodiesel.pdf

NAKAGAWA, J.; CAVARIANI, C.; CASTRO, M.M. Armazenamento de sementes de aveia preta produzidas em solos de diferentes fertilidades. Revista Brasileira de Sementes, v.26, n.2, p.7-14, 2004. http://www. agrolink.com.br/downloads/123299.pdf

PÁDUA, G.P.; VIEIRA, R.D. Deterioração de sementes de algodão durante o armazenamento. Revista Brasileira de Sementes, v.23, n.2, p.255-262, 2001. http://www.abrates.org.br/revista/artigos/2001/v23n2/ artigo35.pdf

RESIO, A.N.C.; AGUERRE, R.J.; SUAREZ, C. Analysis of simultaneous water absorption and water-starch reaction during soaking of amaranth grain. Journal of Food Engineering, v.68, n.02, p.265-270, 2005. http://www.sciencedirect.com/science/article/b6t8j-4cxmt8m2/2/126224924f901d54b3ff40f5db6b0407

SANTOS, S.R.G.; PAULA, R.C. Teste de condutividade elétrica para avaliação da qualidade fisiológica de sementes de Sebastiania commersoniana (Bail) Smith e Dows - Euphorbiaceae. Revista Brasileira de Sementes, v.27, n.2, p.136-145, 2005. http://www.scielo.br/pdf/rbs/ v27n2/a20v27n2.pdf
SCHMIDT, L. Guide to handling of tropical and subtropical forest seed. Denmark: Danida Forest Seed Centree, 2000. 511p.

TOLEDO, M.Z.; FONSECA, N.R.; CESAR, M.L.; SORATTO, R.P.; CAVARIANI, C.; CRUSCIOL, C.A.C. Qualidade fisiológica e armazenamento de sementes de feijão em função da aplicação tardia de nitrogênio em cobertura. Pesquisa Agropecuária Tropical, v.39, n.2, p.124-133, 2009. http://www.revistas.ufg.br/index.php/pat/issue/ view/664

TUNES; L.M.; BARROS, A.C.S.A.; BADINELLI, P.G.; GARCIA, D.C. Armazenabilidade de sementes de cevada colhidas em diferentes épocas. Bioscience Journal, v.26, n.3, p.403-412, 2010. http://www.seer.ufu.br/ index.php/biosciencejournal/article/viewFile/7121/4853

ULLMANN, R.; RESENDE, O.; SALES, J.F.; CHAVES, T.H. Qualidade das sementes de pinhão manso submetidas à secagem artificial. Revista Ciência Agronômica, v.41, n.3, p.442-447, 2010. http://www.ccarevista. ufc.br/seer/index.php/ccarevista/article/viewFile/911/463

VIEIRA, R.D.; KRZYZANOWSKI, F.C. Teste de condutividade elétrica. In: KRZYZANOWSKI, F.C.; VIEIRA, R.D.; FRANÇA-NETO, J.B. (Eds.). Vigor de sementes: conceitos e testes. Londrina, PR: ABRATES, 1999. Cap. 04, p.1-26.

VIEIRA, R.D.; PENARIO, A.L.; PERECIN, D.; PANOBIANCO, M. Condutividade elétrica e teor de água inicial das sementes de soja. Pesquisa Agropecuária Brasileira, v.37, n.9, p.1333-1338, 2002. http:// www.scielo.br/pdf/pab/v37n9/13209.pdf 